\section{Research Square}

Preprints are preliminary reports that have not undergone peer review.

They should not be considered conclusive, used to inform clinical practice, or referenced by the media as validated information.

\title{
Coronary Artery Bypass Grafting in a Patient With Situs Inversus Totalis: A Case Report
}

Atsushi 0i ( $\square$ atsushi.oi319@gmail.com )

Gunma University: Gunma Daigaku https://orcid.org/0000-0002-9121-0999

\section{Wataru Tatsuishi}

Gunma University: Gunma Daigaku

Jun Mohara

Gunma University: Gunma Daigaku

\section{Toshikuni Yamamoto}

Gunma University: Gunma Daigaku

\section{Tomonobu Abe}

Gunma University: Gunma Daigaku

\section{Research Article}

Keywords: situs inversus totalis, dextrocardia, coronary artery bypass grafting

Posted Date: August 13th, 2021

DOI: https://doi.org/10.21203/rs.3.rs-762964/v1

License: (c) (i) This work is licensed under a Creative Commons Attribution 4.0 International License.

Read Full License

Version of Record: A version of this preprint was published at Journal of Cardiothoracic Surgery on March 27th, 2022. See the published version at https://doi.org/10.1186/s13019-022-01807-9. 


\section{Abstract}

Background: Coronary artery bypass grafting in situs inversus totalis patients has been seldom reported in the literature.

Case presentation: A 76-year-old woman visited our hospital for chest pain and dyspnea that had started about 5 years earlier. Coronary angiography revealed triple-vessel disease, and computed tomography showed situs inversus totalis. Coronary artery bypass grafting was performed. In this case, the main operating surgeon stood on the right side of the patient until cardiopulmonary bypass was established and then switched positions to the left side of the patient for anastomosis.

Conclusion: CABG was successfully completed in a patient with situs inversus totalis. The position shift helped improve the safety and ease of the surgery.

\section{Background}

Dextrocardia with situs inversus totalis is a rare congenital anomaly in which all organs are mirrored compared to their normal localization [1]. We herein report a patient with situs inversus totalis who underwent coronary artery bypass grafting $(C A B G)$. We believe that the position of the operating surgeon is important in this clinical setting.

\section{Case Presentation}

A 76-year-old woman visited our hospital for chest pain and dyspnea. The symptoms had started about five years before the visit and had gradually worsened. Her medical history included diabetes mellitus and hyperlipidemia. At the time of admission, her symptoms were Canadian Class 3 . Her heart rate was $73 / \mathrm{min}$, and her blood pressure was $150 / 45 \mathrm{mmHg}$. No rales or murmur were heard on auscultation.

Electrocardiography with right chest lead showed ST depression in the V1 $r$ to V4r lead and ST elevation in the aVL lead. Transthoracic echocardiography revealed diffuse hypokinesis with a left ventricular ejection fraction of the $35 \%$. Blood test findings were within normal limits. Computed tomography (CT) confirmed highly calcific coronary arteries and situs inversus totalis (Fig. 1). Coronary angiography demonstrated 99\% stenosis of the proximal part of the morphologic left anterior descending artery (LAD), $99 \%$ stenosis of the right coronary artery (RCA), and $90 \%$ stenosis of the left circumflex artery (LCx) (Fig. 2). The treatment choice was discussed among the heart team, and CABG was recommended to the patient.

During the operation, the surgeon first stood on the right side of the patient. After median sternotomy was performed, the left and right internal thoracic arteries (LITA and RITA) and saphenous vein graft (SVG) were harvested. Cardiopulmonary bypass was established by cannulation of the aorta and the physiological right atrium. At this time, the surgeon switched to the left side of the patient, placed a root cannula, and then cross-clamped the aorta. The SVG was anastomosed to the RCA, and the LITA was 
anastomosed to the LCx as free grafts. Finally, the RITA was anastomosed in situ to the LAD (Fig. 3). Surgery was completed without any problems. She was extubated four hours after surgery.

The post-operative course was uncomplicated. Post-operative coronary artery angiography showed a sufficient flow.

\section{Discussion}

Dextrocardia in combination with situs inversus totalis is a rare congenital anomaly, with a frequency of $1: 10000[1,2]$. A total of $20 \%$ of situs inversus totalis patients are associated with Kartagener's syndrome. Whereas cardiac abnormalities associated with isolated dextrocardia occur frequently, dextrocardia with situs inversus is associated with $<10 \%$ of cardiac abnormalities and has shown equal frequency to the normal population in terms of coronary artery disease [3]. Fabricius et al. first reported a case of dextrocardia in 1606, and Irvin et al. performed CABG for dextrocardia for the first time in $1980[4,5]$. The first case of off-pump CABG for dextrocardia with situs inversus was reported by Tabry et al. in 2001 [6].

The primary point of argument concerning CABG for dextrocardia involves the standing position of the operating surgeon and the grafting design. Rasheed et al. reported that 18 of 24 cases of CABG for dextrocardia between 1981 and 2007 referenced the standing position, with surgeons standing on the left side in 10 cases, the right side in 5 cases, and both sides in 3 cases [7]. It is important for surgeons to be able to perform their operations easily, so the surgeon in the present case stood on the usual right side until cardiopulmonary bypass was established and then moved to the left side for anastomosis. This approach was particularly effective for anastomosing the free LITA to the LCX, as it is very difficult to perform such anastomosis from the same side of the left ventricular apex. The RITA was anastomosed to the $L A D$, which was most frequently used in previous case reports of CABG for dextrocardia. RITA-to-LAD anastomosis should be the first choice, as in cases of dextrocardia, this is considered theoretically equal to LITA-to-LAD anastomosis, which has been confirmed to have long-term patency [8].

\section{Conclusions}

CABG was successfully completed in a patient with situs inversus totalis. The operation was performed safely by switching the surgeon's standing position and then selecting the most appropriate bypass grafts.

\section{List Of Abbreviations}

CABG

Coronary artery bypass grafting

CT

Computed tomography

LAD 
Left anterior descending artery

RCA

Right coronary artery

LCx

Left circumflex artery

LITA

Left internal thoracic arteries

RITA

Right internal thoracic arteries

SVG

Saphenous vein graft

\section{Declarations}

Ethics approval and consent to participate

Not applicable.

\section{Consent for publication}

We have obtained written informed consent from the patients to publish this report.

\section{Availability of data and materials}

Not applicable.

\section{Competing interests}

The authors declare that they have no competing interests.

\section{Funding}

Not applicable.

\section{Authors' contributions}

OA wrote the manuscript. WT did the literature search. TA and WT conceived and designed the report. All authors read and approved the manuscript.

\section{Acknowledgements}

Not applicable.

\section{References}


1. Zhigalov K, Ponomarev D, Sozkov A, Kadyraliev B, Easo J, Weymann A. Coronary Artery Bypass Grafting in a Patient with Situs Inversus Totalis. Am J Case Rep. 2019;20:806-9.

2. Subash S, Simha PP, Manjunatha N. Off-pump Coronary Artery Bypass Surgery in a Patient with Dextrocardia and Situs Inversus: Anesthetic, Surgical Consideration and Role of Transesophageal Echocardiography. Heart Views. 2017;18(3):100-3.

3. Hynes KM, Gau GT, Titus JL. Coronary heart disease in situs inversus totalis. Am J Cardiol. 1973;31(5):666-9.

4. Grey DP, Cooley DA. Dextrocardia with situs inversus totalis: Cardiovascular surgery in three patients with concomitant coronary artery disease. Cardiovasc Dis. 1981;8(4):527-30.

5. Irvin RG, Ballenger JF. Coronary artery bypass surgery in a patient with situs inversus. Chest. 1982;81(3):380-1.

6. Tabry IF, Calabrese J, Zammar H, Abou-Kasem K, Akeilan H, Gharbieh N, et al. Case report: off-pump total myocardial revascularization for dextrocardia and situs inversus. Heart Surg Forum. 2001;4(3):251-3.

7. Saad RA, Badr A, Goodwin AT, Dunning J. Should you stand on the left or the right of a patient with dextrocardia who needs coronary surgery? Interact Cardiovasc Thorac Surg. 2009;9(4):698-702.

8. Cameron A, Davis KB, Green G, Schaff HV. Coronary bypass surgery with internal-thoracic-artery grafts-effects on survival over a 15-year period. N Engl J Med. 1996;334(4):216-9.

\section{Figures}




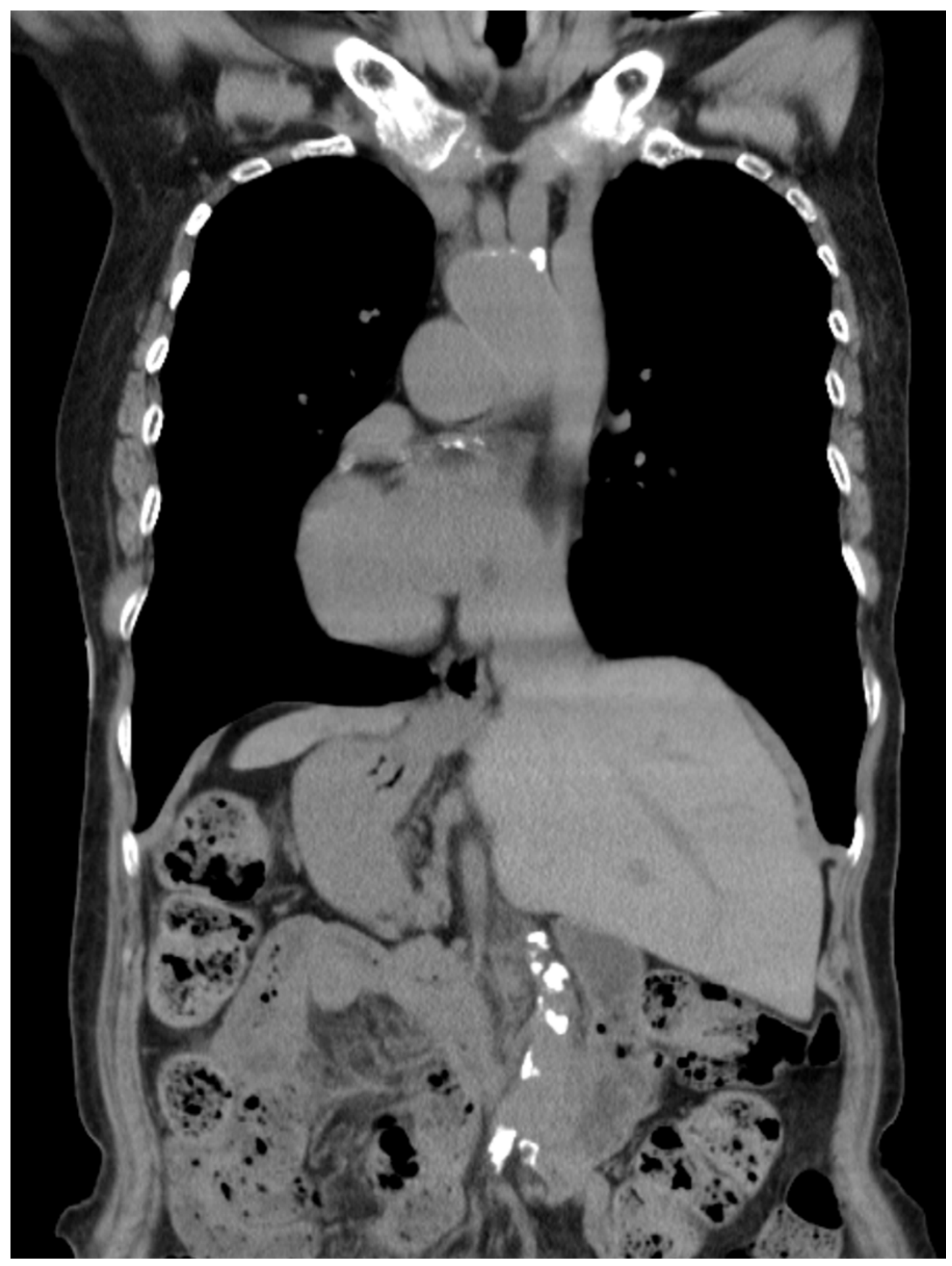

Figure 1

Preoperative computed tomography. All organs, including the cardiovascular system, are mirrored compared to their normal localization 


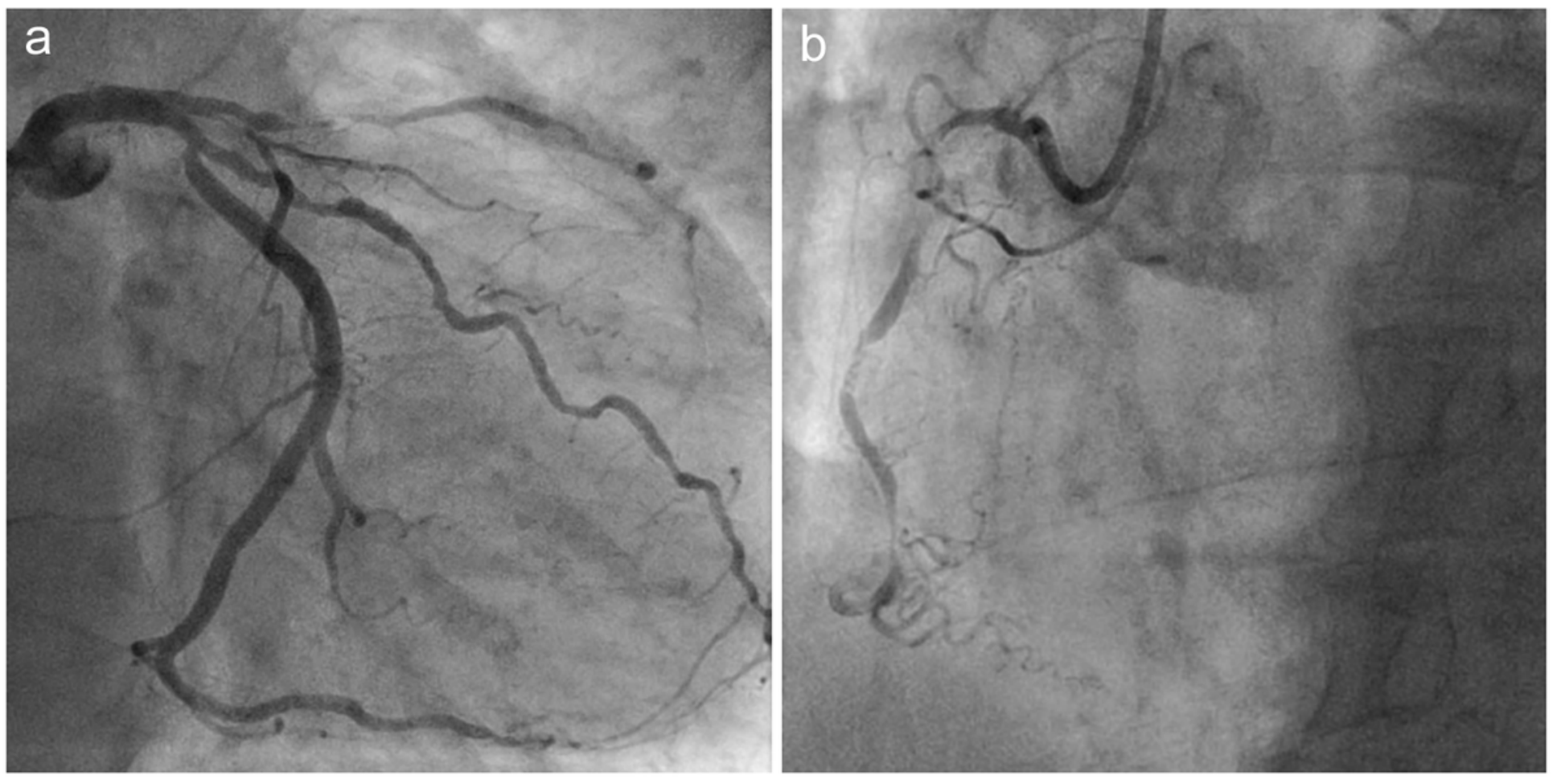

Figure 2

Preoperative coronary angiography. a Stenosis of the left anterior descending artery by $99 \%$, stenosis of the left circumflex artery by $90 \%$. b Stenosis of the right coronary artery by $99 \%$
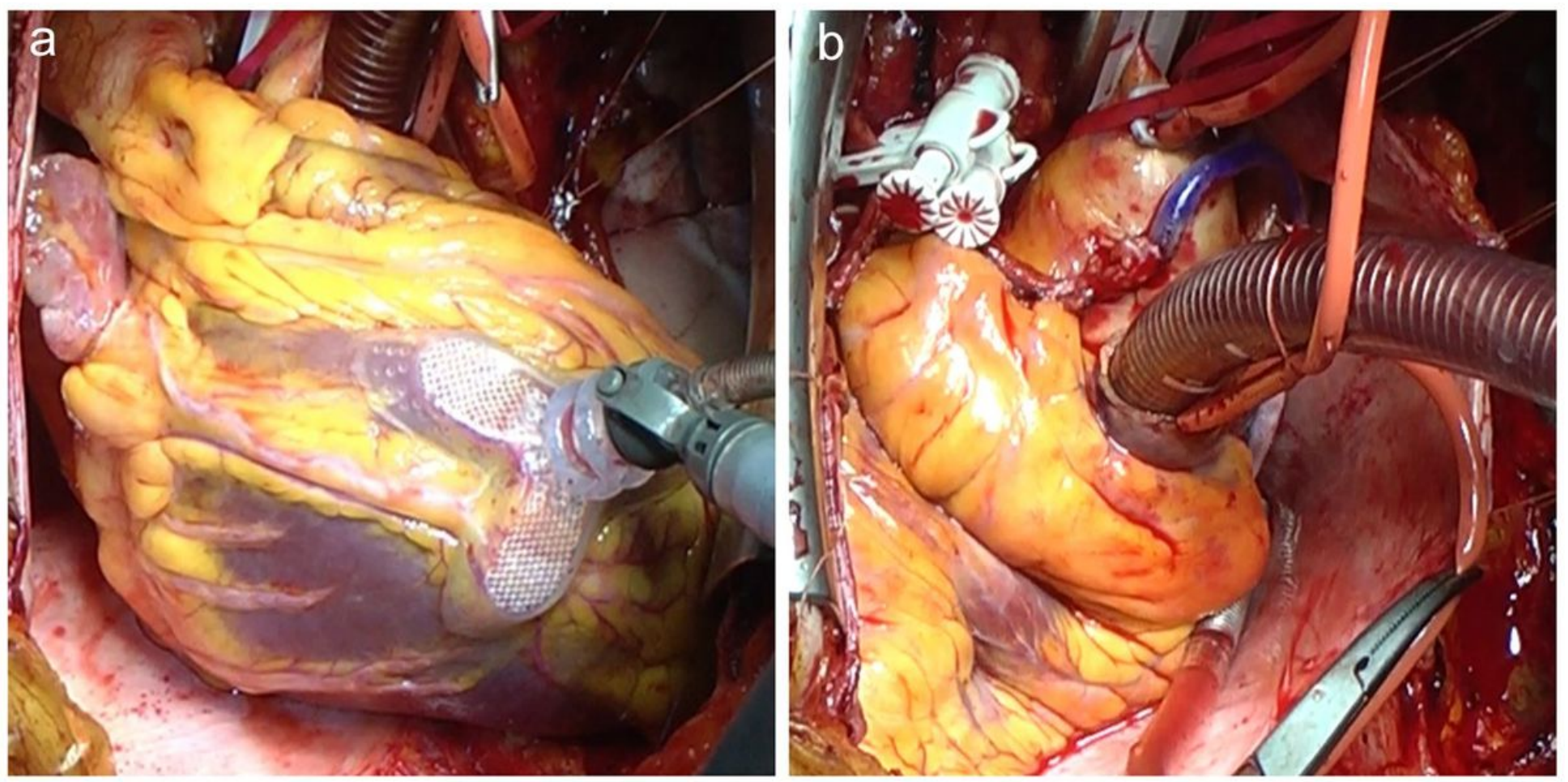

Figure 3 
Intraoperative photographs. a View of the LCx. Approaching the anastomosis site from the right side of the patient is difficult. $b$ End of the anastomosis

\section{Supplementary Files}

This is a list of supplementary files associated with this preprint. Click to download.

- CAREchecklistEnglish2013.pdf 